\title{
Methodology for real impact assessment of the best location of distributed electric energy storage
}

\author{
José Gonçalves ${ }^{\mathrm{a}, \mathrm{b}, *}$, António Martinss ${ }^{\mathrm{a}, \mathrm{b}}$, Luís Neves ${ }^{\mathrm{c}, \mathrm{a}, \mathrm{b}}$ \\ a Energy for Sustainability Initiative, University of Coimbra, Portugal \\ b INESCC - Institute for Systems Engineering and Computers at Coimbra, Portugal \\ ${ }^{\text {c }}$ Polytechnic Institute of Leiria, Portugal
}

\section{A R T I C L E I N F O}

\section{Article history:}

Received 17 September 2015

Received in revised form 2 April 2016

Accepted 19 May 2016

Available online 20 May 2016

\section{Keywords:}

Distributed electric energy storage

Genetic algorithms

Electric networks

Energy profiles

Energy service

Methodology

\begin{abstract}
A B S T R A C T
This paper presents a methodology to provide a decision maker, e.g. the distribution system operator, information on the associated impacts of the operation of distributed electric energy storage systems $\left(\right.$ ESS $\left.^{1}\right)$ in an urban environment, in order to support the choice of the best locations of storage units. The developed methodology uses three types of profile prototypes based on actual data, obtained through clustering techniques. These profiles, which include electricity demand, electricity prices and renewable electricity production, are used to optimize the placement of electric energy storage units. The paper considers expected attitudes of the main stakeholders towards distributed electric ESS implementation, and discusses possible regulatory framework options to define the distributed electric ESS business model.

The model was applied to a case study using the nanophosphate lithium-ion battery technology as an example. Results show a significant influence of the charge/discharge profile of batteries on the choice of their best locations.
\end{abstract}

(c) 2016 Elsevier Ltd. All rights reserved.

\section{Introduction}

The need to combine intermittent renewable generation, continuous load growth, increasing power quality requirements of electronic loads and higher regional power transfers in a nowadays largely interconnected network, presents new challenges to power systems.

These new challenges can lead to a complex and less secure power system operation, especially because power plants may not be able to follow new demands as a result of technical, economic, environmental, and/or governmental regulation constraints (Ribeiro, Johnson, Crow, Arsoy, \& Liu, 2001; Vitorino, Jorge, \& Neves, 2013a; Vitorino, Jorge, \& Neves, 2013b).

In the context of smart grids and micro grids, distributed electric energy storage systems $\left(\right.$ ESS $^{2}$ ) are presented as an option to enable the optimal use of resources, by providing the capability of effectively balancing supply and demand (EPRI, 2010). However, a

\footnotetext{
* Corresponding author at: INESCC - Institute for Systems Engineering and Computers at Coimbra, Edifício DEEC, Pólo II, R. Silvio Lima, 3030-290 Coimbra, Portugal.

E-mail address: uc2011186044@student.uc.pt (J. Gonçalves).

1 ESS - Energy storage systems.

2 ESS - Energy storage systems.
}

methodology is needed to evaluate the impact of storage as well as the best allocation of distributed electric ESS units in order to provide specific energy services to the network.

The methodology presented in this paper makes use of daily profiles of load, electricity price and renewable generation obtained through data clustering methods. The optimization process uses a genetic algorithm to provide the decision maker a Pareto front of possible solutions for the location and number of distributed electric ESS units, as a result of considering four objectives: minimization of network energy losses $\left(\mathrm{NEL}^{3}\right)$, maximization of network energy rate benefit $\left(\mathrm{NERB}^{4}\right)$, minimization of network voltage quadratic mean deviation $\left(\mathrm{NVqmd}^{5}\right)$ and minimization of the network storage annualized cost $\left(\mathrm{NSAC}^{6}\right)$.

Different locations for the ESS unit could affect the network energy flows and its associated losses as well as the deviation in the bus voltages. The number and location of batteries and their management naturally imply different investment costs and also cause different benefits of the trade of stored energy. These four objec-

\footnotetext{
${ }^{3}$ NEL - Network energy losses.

${ }^{4}$ NERB - Network energy rate benefit.

5 NVqmd - Network voltage quadratic mean deviation.

${ }^{6}$ NSAC - Network storage annualized cost.
} 
tives are commonly referred in the literature (Chen, Hsieh, Yang, Yang, \& Liao, 2013; Lassila, Haakana, Tikka, \& Partanen, 2012; Leou, 2012), and therefore a multiobjective approach was chosen.

\section{Electrical energy storage systems}

The rising cost of fuels and the increasing penetration of renewable energy generation units led to the need of rethinking the management of the electricity grid. Although considered economically unfeasible in the past, the concept of energy storage, either centralized or decentralized, is presented today as an opportunity to solve many problems of network capacity and reliability (Divya \& Østergaard, 2009; Ribeiro et al., 2001).

According to Divya and Østergaard (2009), some of the reasons for the presently small deployment of storage systems are probably the existence of a large number of conventional generators that can be adjusted to match the load demand and the interconnection of power systems, which help balancing load demand variations. Nevertheless, this scenario is changing due to the present high rate of deployment of intermittent renewable energy sources, such as wind power generation, and the existing capacity limits of the networks interconnections.

Moreover, some limitations for the use of these systems are the possible reluctance of a distribution system operator to integrate resources not under his control (Sovacool \& Hirsh, 2009). To overcome these barriers, it is important to assess, in each case, the benefits of this type of systems, namely by developing operational tools to select the amount and location of these resources, optimize the operational cost and assess the benefits of storage during the planning phase (Divya \& Østergaard, 2009; EPRI, 2010).

According to Divya and Østergaard (2009) previous research assessing the impact of ESS on the power system operation and economics has been focused on economic/optimal sizing, often taking a unique perspective (e.g. the consumer, the network operator). Namely, ESS has been modelled from the point of view of cost (economic models) or with a focus on the assessment of operational benefits, modelling the ESS response to power system disturbances at appropriate time scales (operational models).

Most studies doing economic analysis of energy storage consider vertically integrated utilities and do not incorporate the market models to assess the benefits of ESS in the present day deregulated market. Some of those methodologies only considered isolated impacts and disregard the ESS management scheme, i.e. the choices regarding the charging and discharging schedule (Kempton \& Tomić, 2005; Schoenung, 2011).

Bradbury, Pratson, and Patiño-Echeverri (2014) showed that technological characteristics, such as round-trip efficiency and selfdischarge are important issues to the ESS viability and should be assessed, as a result of the comparison of 14 technologies and 7 regional markets, also pointing the need for rewarding the added flexibility by ESS with market instruments as one possible solution to help ESS deployment. These authors used the internal rate of return as an indicator of economic viability.

Divya and Østergaard (2009) refer that the majority of the studies concerning power systems analyses usually do not refer to any particular battery type, or to any limitation to the performance of ESS. However, continuous science evolution is changing this scenario with contributions of authors that are embodying the technology characteristics into theirs models (Dufo-López \& Bernal-Agustín, 2015; Fossati, Galarza, Martín-Villate, \& Fontán, 2015).

Regarding the assessment of network services and the associated technical characterization of the generation mix, some authors used either island case studies or simplified grid models in order to reduce the dimension of the problem (Almeida, Lopes, Soares, \&
Seca, 2011). Such studies are usually only focused on one type of approach, technical or economic, and usually do not provide more than one option for a decision maker to choose from, assuming and not revealing implicit tradeoffs.

Ippolito, Di Silvestre, Riva Sanseverino, Zizzo, and Graditi (2014) developed a multi-objective assessment to obtain a suitable daily profile of the state of charge of the batteries, considering a distributed ESS, namely the location of storage units, within an islanded distribution network. In order to define the objective functions, namely to minimize the total daily generation cost, to minimize the NEL and to minimize greenhouse gas emissions, these authors considered the interests of the distribution system operator embodied in the environmental and the economical dispatch, using an ESS size defined heuristically.

Also considering the network operator perspective (to minimize the network operating cost) Fossati et al. (2015) presented a new method for sizing the energy storage system, namely by finding the optimal energy and power capacities of the ESS, using predefined scenarios. The proposed method makes use of a genetic algorithm to optimize simultaneously the energy management strategy and the ESS capacity. The obtained results showed that the optimal size of ESS is dependent on the expected lifetime and the associated network operating costs.

Considering the consumer interest, Dufo-López and BernalAgustín (2015) present a methodology to evaluate ESS considering both battery degradation and ESS capital costs. The developed methodology introduced the need for a regulatory framework to increase the interest for ESS. Based on Spanish "super-valley" EV time-of-use tariff for electric vehicles, the authors proposed a time-of-use electricity tariff with a significant difference between off-peak and on-peak prices to increase the income from buying and selling energy. Even with a feed-in-tariff results showed that acquisition costs are the main limitation for ESS viability.

The use of electric vehicles to provide energy services is commonly referred in the literature (Divya et al., 2010; Lassila et al., 2012), but most of the works are more concerned with the unpredictability/availability of the electric vehicles than with its optimal distribution on the grid and with the associated impacts (Battistelli, Baringo, \& Conejo, 2012).

Lassila et al.(2012), considered distributed storage management using intelligent charging and discharging schemes, by including control strategies defined by the distribution system operator based on bidirectional data exchange. Such approach provides a basis for assessing the release of network capacity and for studying a more efficient operation (e.g. decreasing NEL, avoiding short interruptions and shaving power peaks or smoothing load curves).

In order to obtain a compromise between the objectives of the network operator and the objectives of consumers or private investors, as a way of representing the perspective of the whole society, the authors propose a new methodology which takes into account a management scheme for battery charging and discharging to obtain a Pareto front.

The proposed methodology enables the decision maker to choose from a set of possible ESS allocation options, considering four objective functions (two economic and two operational). The ability to define a specific charge/discharge management scheme and to assess its associated impacts, both technical and economical, improves the perception of the relevant attributes of the distributed electric ESS options. A pricing scheme for the energy released by ESS is also proposed by the authors, based on the existing legal framework for renewable energy generation, which aims at contributing to the definition of a viable business model for distributed ESS.

More detailed literature reviews of the ESS operation, application, as well of the barriers and impact assessment were presented by the authors in Gonçalves, Martins, and Neves (2013) and in Gonçalves, Vitorino, Neves, and Martins (2013). 


\section{Framework for trading stored energy}

Being distributed energy storage an emerging technology solution with no stabilized legal framework defined, the present paper also aims to contribute with insights for the integration and management of electric ESS within a radial distribution system.

Considering the current Portuguese legal framework as a reference for our case study, there are two kinds of players in the production segment: the ordinary regimen producer and the special regimen producer.

A special regimen producer is any small renewable energy producer, waste disposal plant, cogeneration plant, or microproduction power plant with rated power below $5.75 \mathrm{~kW}$ (ERSE, 2009).

Ordinary regimen producers are energy producers that participate in the power system control, namely the big thermoelectric units and large hydroelectric power plants.

Considering the previous definition for special regimen producer, an ESS can be seen as a special regimen producer-energy market player. In fact, one of the major benefits of ESS will be to help maximizing the benefit of renewable production, even increasing its share in the production mix, due to a better match between the availability of supply and the variation of the demand. However, this feature is not yet accounted in the current legislation.

Currently the Portuguese last resort retailer is obliged to purchase all energy produced by special regimen producers, with administratively defined prices, or resulting from a bidding process upper bounded by values set by the government (to generate energy to the network). These values are based on the avoided costs of not building new conventional facilities as well as on the avoided energy costs (fuel costs) and avoided environmental costs (avoided $\mathrm{CO}_{2}$ emissions cost) (MIBEL' council of regulators, 2011).

Fig. 1 presents the evolution of the average electricity prices from 2000 to 2012, including the regulated market and the special regimen producer market (ERSE, 2013).

Using Fig. 1 as a reference, the present study proposes the electric ESS as a special regimen producer that buys energy at a daily market electricity price and sells at special regimen producer prices in high demand periods. The justification for this choice is that distributed electric ESS may play an important role to support the investment in renewable energy, namely of intermittent nature, avoiding the use of backup thermal generation. In this study, an average special regimen producer tariff of $101.3 € / \mathrm{MWh}$ (referring to 2008) was used to match the period for which consumption data were available.

\section{Methodological proposal applied to a case study}

The proposed methodology provides a Pareto front for each considered scenario, using a multi-objective optimization algorithm, based on network, technical and service characterization data, in order to obtain the best possible distributed electric ESS locations, as presented in Fig. 2.

The methodology depicted in Fig. 2 presents the three main steps to assess the impact of distributed electric ESS for a given characterization (Step 1) and the associated working definition (step2), namely by clustering the case specific yearly data and by defining plausible management schemes of the ESS units based on the pricing scheme framework defined to encourage the adoption of the proposed solution.

The assessment of the impacts is performed using an optimization algorithm, which uses two technical and two economic objective functions to define the admissible Pareto fronts. For the considered case study, the genetic algorithm population was assumed to be composed of 150 individuals and a maximum number of 100 generations was defined.

\subsection{Formulation of the multi-objective optimization problem}

Considering a $24 \mathrm{~h}$ time horizon and the chosen scenarios, the assessment of the best locations for distributed electric ESS consists in the identification of the distribution network nodes in which energy storage elements will most contribute to minimize NEL, NVqmi and NSAC, and to maximize the NERB associated with the daily purchase and sale of energy in different time periods.

In Table 1 the mathematical formulations of the objective functions for the optimization process are presented.

The NEL objective function, to be minimized, is the sum of the network energy losses in all the $n$ branches of the medium voltage distribution network during the whole day. The elementary time interval is a quarter-hour $\left(t_{j}=0.25 h\right)$ so the data set has 96 values $(\mathrm{m}=96)$.

The NVqmd objective function, to be minimized, is the network voltage quadratic mean deviation in p.u. for all individual voltage deviations $(V D)$ in the $N$ network buses, compared with the voltage reference value, during each elementary time interval $t_{j}$.

The NSAC objective function, to be minimized, is the associated annualized cost in EUR for installing $x$ units of distributed electric ESS with an individual capital $\operatorname{cost} c_{c}$ and the capital recovery factor, where $d$ is the dimensionless discount rate and $y$ the expected life of the equipment, measured in years;

The NERB objective function considers the energy tariff $(C)$ and the required energy $(E)$, for charging $(c h)$ and discharging (dch) periods, during the 96 elementary time intervals.

\subsection{Implementation of the optimization algorithm}

Genetic algorithms belong to the larger class of evolutionary algorithms, comprising a search technique that provides exact or approximate solutions, based on the evolution of organisms. Genetic algorithms have been widely used in several power systems problems, such as economic dispatch, rearrangement of power networks, optimal placement of capacitors or inductors, and optimal power flow analysis (Chen et al., 2013; Vitorino, Neves, \& Jorge, 2009). Genetic algorithms and other meta-heuristics are particularly suited to solve problems of combinatorial nature, where other types of optimization methods reveal to be unsuitable due to the non-trivial nature of the mathematical modelling requirements.

By the reasons presented above the authors chose the Nondominated Sorting Genetic Algorithm II (NSGA-II ${ }^{7}$ ) as a tool to solve the multi-objective problem formulated in the current work. This algorithm has proven to be efficient, especially in power distribution operation and planning problems (Vitorino et al., 2013a). More detailed information about this algorithm can be found in (Deb, Pratap, Agarwal, \& Meyarivan, 2002).

The used method presented promising results regarding the performance in terms of speed of convergence and stability, as presented in Vitorino et al. (2013b) and Vitorino, Neves et al. (2009), when compared to conventional genetic algorithms or particle swarm optimization algorithm.

The definition of the available nodes for the installation of storage units is made by the decision maker, based on technical criteria such as which buses have critical load factors or available space. The decision maker can easily define the availability of a specific node for ESS installation using a binary coding ( 1 or 0 ) as exemplified in Table 2 .

This technique will create a matrix of chromosomes with total length equal to the predefined number of individuals whose num-

\footnotetext{
7 NSGA-II - Non-dominated Sorting Genetic Algorithm II.
} 


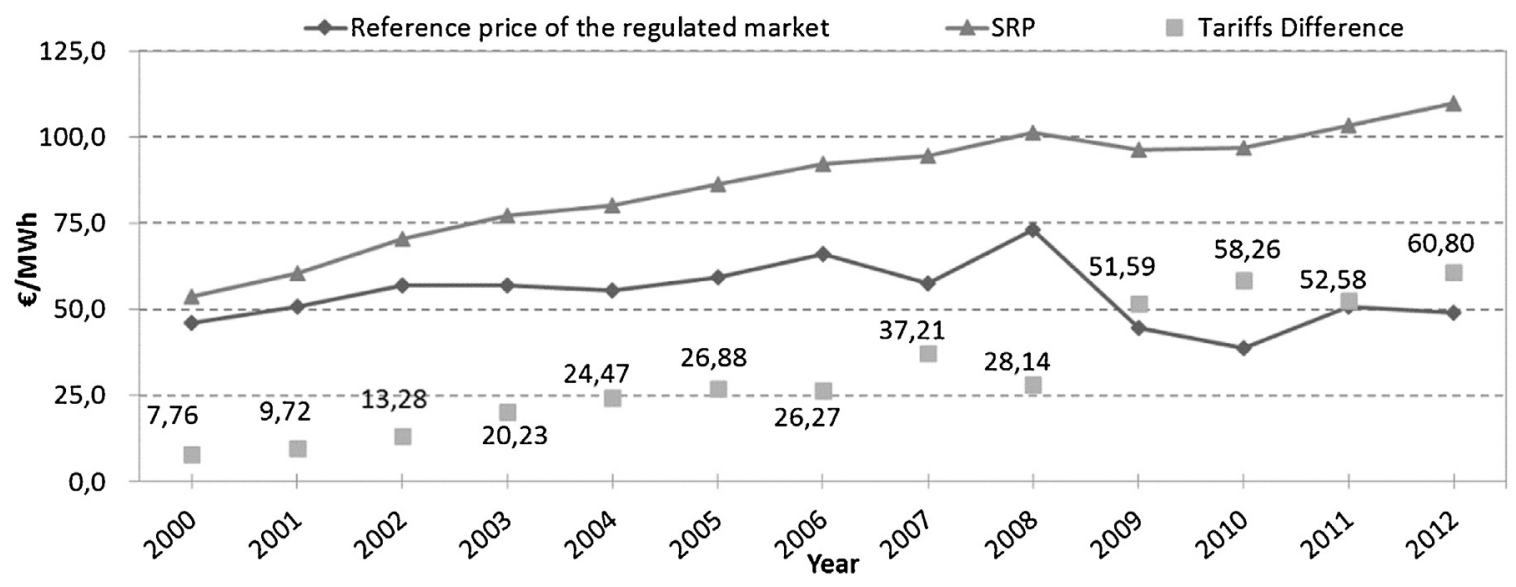

Fig. 1. Average annual cost between special regime producers and regulated market (ERSE, 2013).

Step 1:

Step 2:

Step 3:

Characterization Working definition Optimiz. Process

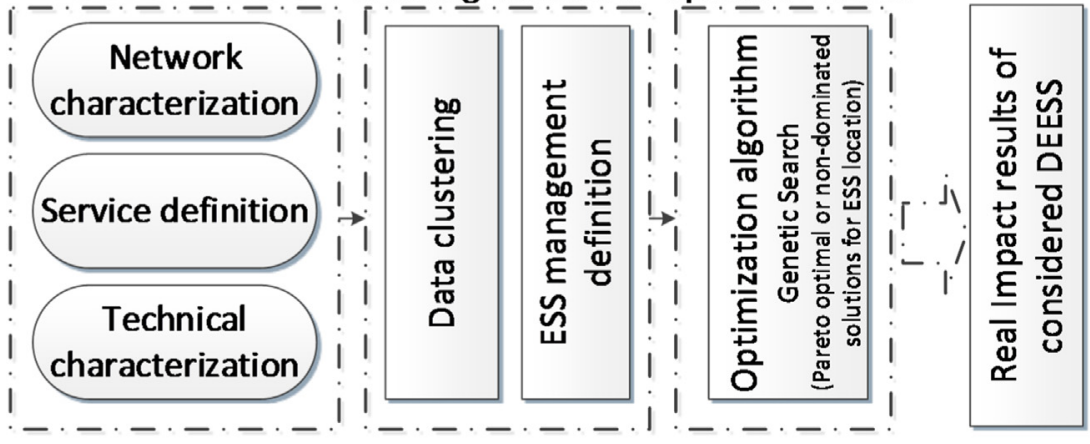

Fig. 2. Proposed methodology for DEESS assessment using the optimization algorithm.

Table 1

Objective functions for the optimization process.

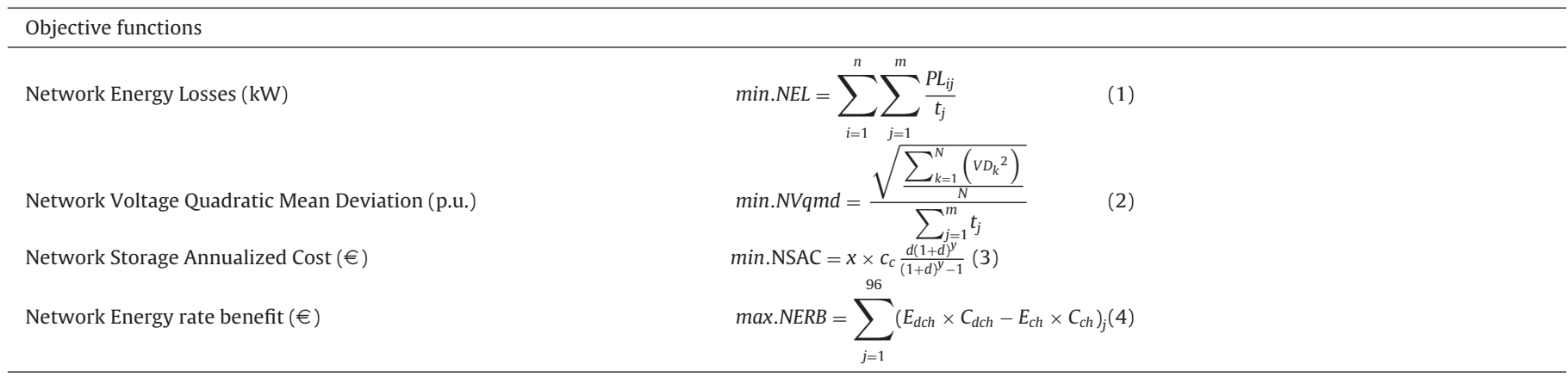

Table 2

Coding technique for available buses identification.

\begin{tabular}{llllllll}
\hline Node number & 1 & 2 & 3 & 4 & $\ldots$ & $\mathrm{n}-1$ & $\mathrm{~N}$ \\
Availability Status & 0 & 1 & 1 & 0 & $\ldots$ & 1 & 0
\end{tabular}

ber of chromosome bits equals the number of available nodes for ESS installation.

The used genetic data are presented in Table 3, being quite similar to those used in Vitorino, Jorge, and Neves (2009) for a quite different application.

In Table 3 variables Pmmin and Pmmax represent the minimum and maximum variation range of mutation probabilities, respectively. The Pcmin and Pcmax variables represent the minimum and
Table 3

Dynamic data for the optimization algorithm.

\begin{tabular}{lllllll}
\hline Designation & Pmmin & Pmmax & Pcmin & Pcmax & Bmin & Bmax \\
Value & 3 & 25 & 50 & 100 & 0 & 100 \\
\hline
\end{tabular}

maximum variation range of crossover probabilities, respectively. Finally, the Bmin and Bmax variables represent the minimum and maximum bound for the diversity of each generation.

\subsection{Data clustering}

In order to define a charge/discharge profile of the storage elements and to evaluate the economical value of the operation, 
Table 4

Representativeness of daily price profile prototypes.

\begin{tabular}{ll}
\hline Daily price profile & Profile representativeness \\
\hline DP1 & $9.8 \%$ \\
DP2 & $27.6 \%$ \\
DP3 & $29.5 \%$ \\
DP4 & $18.9 \%$ \\
DP5 & $14.2 \%$ \\
\hline
\end{tabular}

Table 5

Representativeness of load demand profile prototypes.

\begin{tabular}{ll}
\hline Load demand profile & Profile representativeness \\
\hline LD1 & $14.2 \%$ \\
LD2 & $16.7 \%$ \\
LD3 & $25.1 \%$ \\
LD4 & $29.5 \%$ \\
LD5 & $14.5 \%$ \\
\hline
\end{tabular}

Table 6

Representativeness of renewable energy profile prototypes.

\begin{tabular}{ll}
\hline Renewable energy profile & Profile representativeness \\
\hline RE1 & $17.2 \%$ \\
RE2 & $22.1 \%$ \\
RE3 & $26.5 \%$ \\
RE4 & $21.0 \%$ \\
RE5 & $13.1 \%$ \\
\hline
\end{tabular}

prototypes of daily load profiles, as well as of electricity prices profiles and of renewable generation profiles, were needed.

Considering the available records of full years of daily diagrams, representative prototypes could be obtained by applying a clustering process, allowing the clustering of daily diagrams into groups of similar characteristics. For this purpose, a process was developed to obtain such profiles, namely through a hierarchical clustering method $\left(\mathrm{HM}^{8}\right)$ and an artificial neural networks $\left(\mathrm{ANN}^{9}\right)$ method (Everitt, Landau, Leese, \& Stahl, 2011; Mooi \& Sarstedt, 2010; Simon, 2013). The two chosen methods are considered very versatile and well performing (Maimon \& Rokach, 2005), and represent two different approaches to clustering. The comparison of the results of both methods is then also a way to validate the process.

Both clustering processes resulted in 5 clusters, after analyzing the tree dendogram and the inflection point of the curve that relates the distances between clusters with the number of clusters (Salvador \& Chan, 2004).

The representativeness of each cluster, in terms of the number of daily profiles that belong to it, is listed in Tables 4-6. A prototype was defined for each cluster as the average profile of its members.

Fig. 3 shows a few examples of the prototypes obtained using the HM and the ANN methods. It is possible to verify that the differences between prototypes obtained with different methods are negligible.

\subsection{Management scheme definition}

Several authors have used different approaches, depending on the expected service to provide, to assess the charge/discharge profiles (Chen et al., 2013; Lassila et al., 2012).

The charging and discharging daily pattern for the ESS may vary significantly, depending on the decision maker preferences. From the literature, three plausible management schemes were identified:

\footnotetext{
${ }^{8} \mathrm{HM}$ - hierarchical clustering method.

9 ANN - artificial neural networks.
}

1. Management scheme A - To maximize benefit from daily energy spot market prices;

2. Management scheme B - To minimize daily energy distribution NEL;

3. Management scheme $\mathrm{C}$ - To maximize benefit from renewable wind generation.

Within the considered management schemes, each scenario to be tested during the optimization procedure led to the definition of the associated charge/discharge management scheme of the ESS. In order to increase the duration of the charge and discharge daily periods, as a general approach, the use of the average value of each daily data prototype was considered as a target for management schemes A and B. The storage units should charge and discharge when the daily profile presents values below or above the reference value, respectively.

Fig. 4 represents the electricity prices difference to the average considering prototype \#5 from the set of developed prototypes, where the ESS charge/discharge profile is defined with -1 for the best charging period, 1 for the best discharging period and 0 for the standby mode.

The network energy losses were calculated using the network load profiles, resulting on a daily evolution as presented in Fig. 5.

Regarding the role of energy storage for the integration of renewable generation, particularly wind-based generation, a main motivation of storing energy in periods of higher generation power to be delivered in periods of lower generation power was assumed, in order to stabilize the overall balance between generation and load profiles.

Once both generation and load diagrams were subjected to a normalization procedure during the clustering process, the charge/discharge profile was derived from the difference between load demand profiles and wind generation prototypes, as presented in Fig. 6. The idea is that this difference, if negative, represents the periods when generation is excessive, and if positive, represents the periods when stored energy should be delivered because demand is high and renewable generation is not.

Given the difference between the two prototypes, the procedure to obtain the charge/discharge binary vector is similar to what was done for previous scenarios, resulting in diagrams comparable to the one represented on Fig. 7.

In order to define the scenarios of simulation, the authors combined the prototypes in the following manner per each considered management scheme, obtaining a total of 75 scenarios:

- Considering the management scheme A objective: Combination of the five energy market rates prototypes with the five possible distribution load demand prototypes, resulting in 25 scenarios.

- Considering the management scheme B objective: Combination of the five energy market rates prototypes with the five possible distribution load demand prototypes, resulting in 25 scenarios.

- Considering the management scheme C objective: Combination of the five distribution load demand prototypes with the five possible wind generation prototypes, resulting in 25 scenarios.

During the process, a lack of correlation was observed between electricity prices and renewable generation patterns. Since most of the energy sector players react to price stimulus, this lack of correlation may lead to management decisions that will not favour renewable generation.

Moreover, a small deviation between the evolution of market electricity prices and the evolution of the distribution grid load demand was also verified in this case, this deviation depending on the substation geographical location but also with more or less relevance, according to the specific day chosen. 


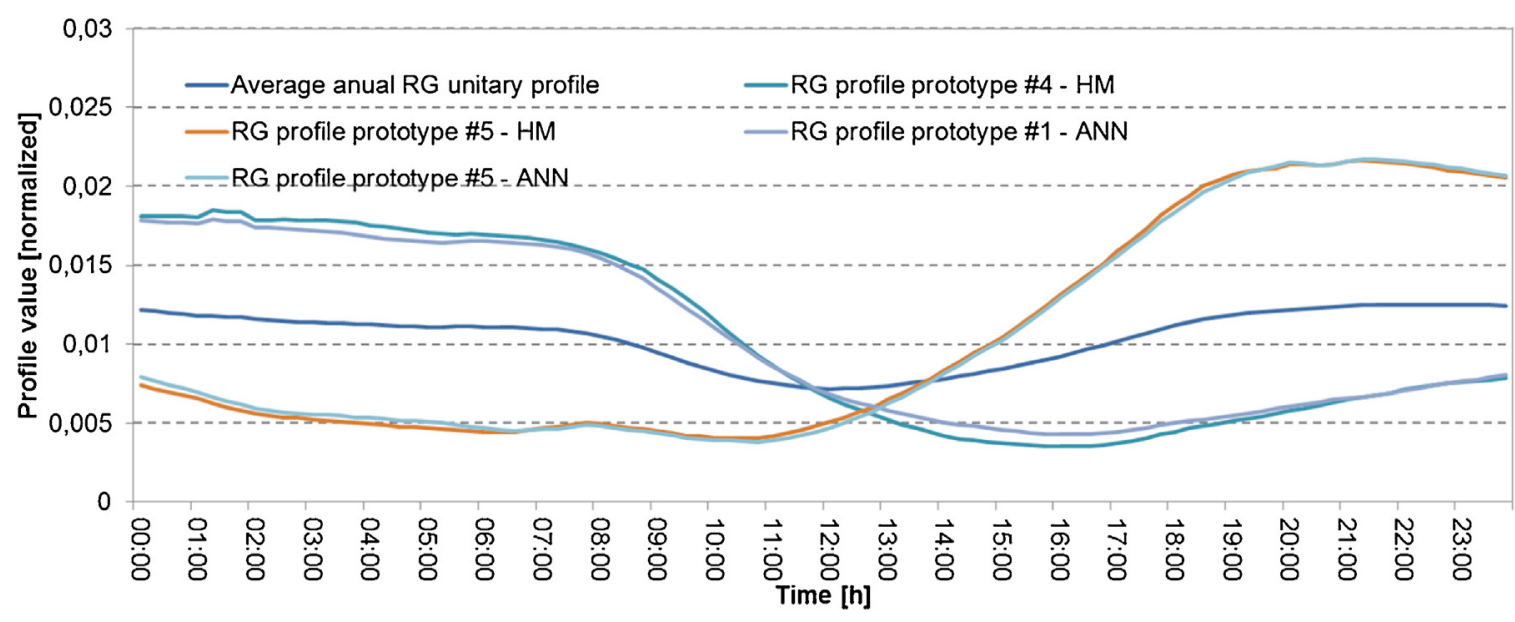

Fig. 3. An example of renewable profiles using the HM and the ANN method.

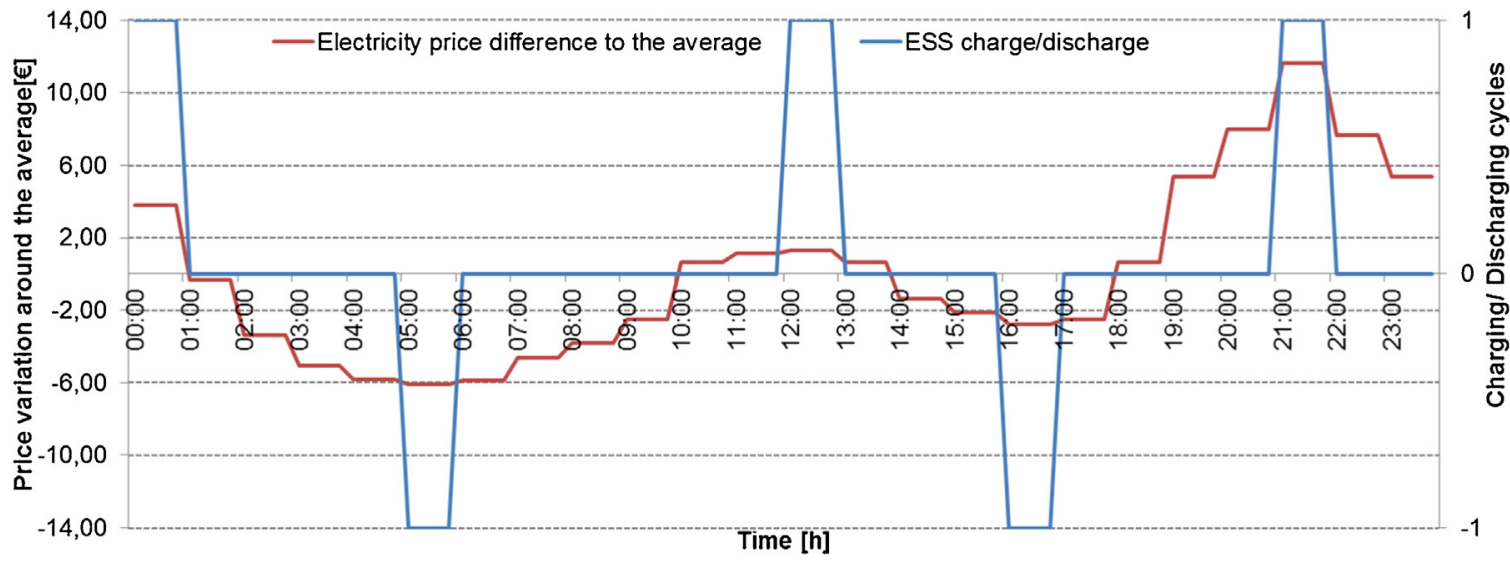

Fig. 4. Analysis of the electricity price difference to the average for daily price prototype\#5.

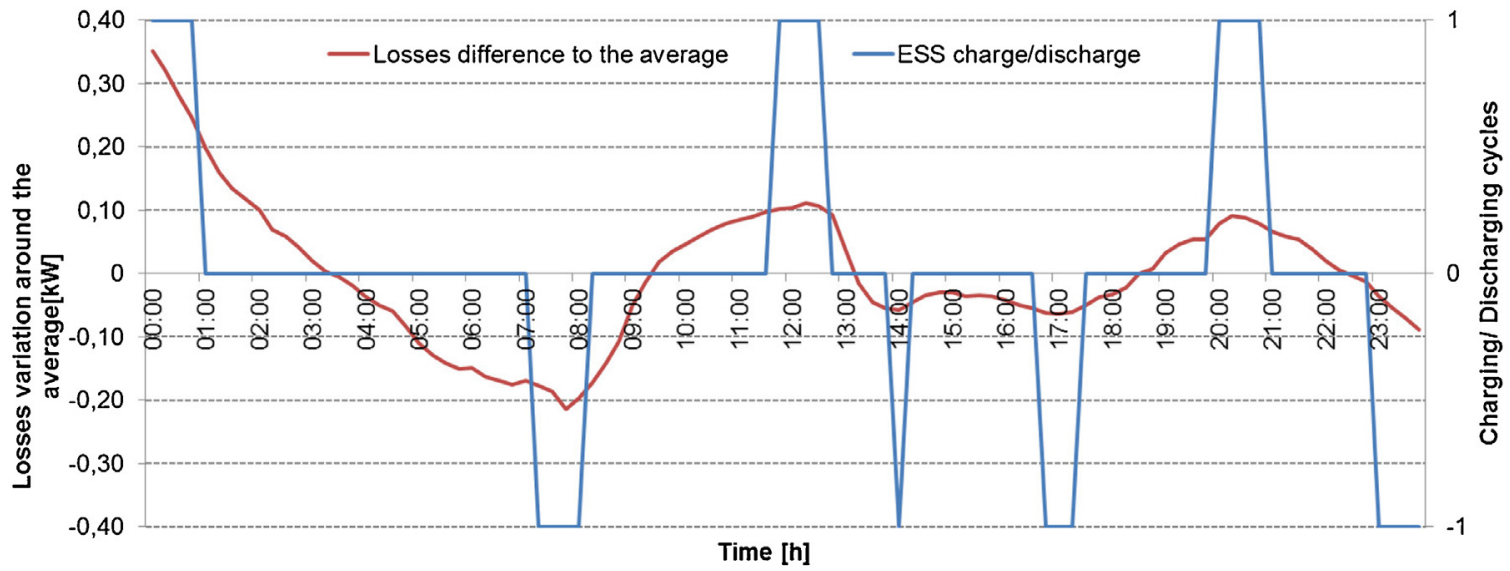

Fig. 5. Analysis of the NEL difference to the average for load demand prototype\#1.

Considering the defined schedule for charging and discharging the storage units, as exemplified in Figs. 4, 5 and 7, a charge/discharge matrix was built with data from the 75 scenarios, to be used in the optimization process.

\subsection{Technical characteristics of the ESS units}

The assessment of the distributed electric ESS evaluation impact is not independent of the considered technology, since the specific technological characteristics presented by different manufacturers lead to different results of the assessment process.

The selected nanophosphate lithium ion battery with the respective power converter were characterized according to the data available at the manufacturer website and technical publications (A. Systems, 2012, 2013; Vartanian, 2010). According to these data, a total energy of $61.13 \mathrm{Wh} /$ cell was assumed, corresponding to $95 \%$ of depth-of-discharge. This option was based on the manufacturer information indicating more than 7000 cycles even with 100\% depth-of-discharge (A. Systems, 2013). 

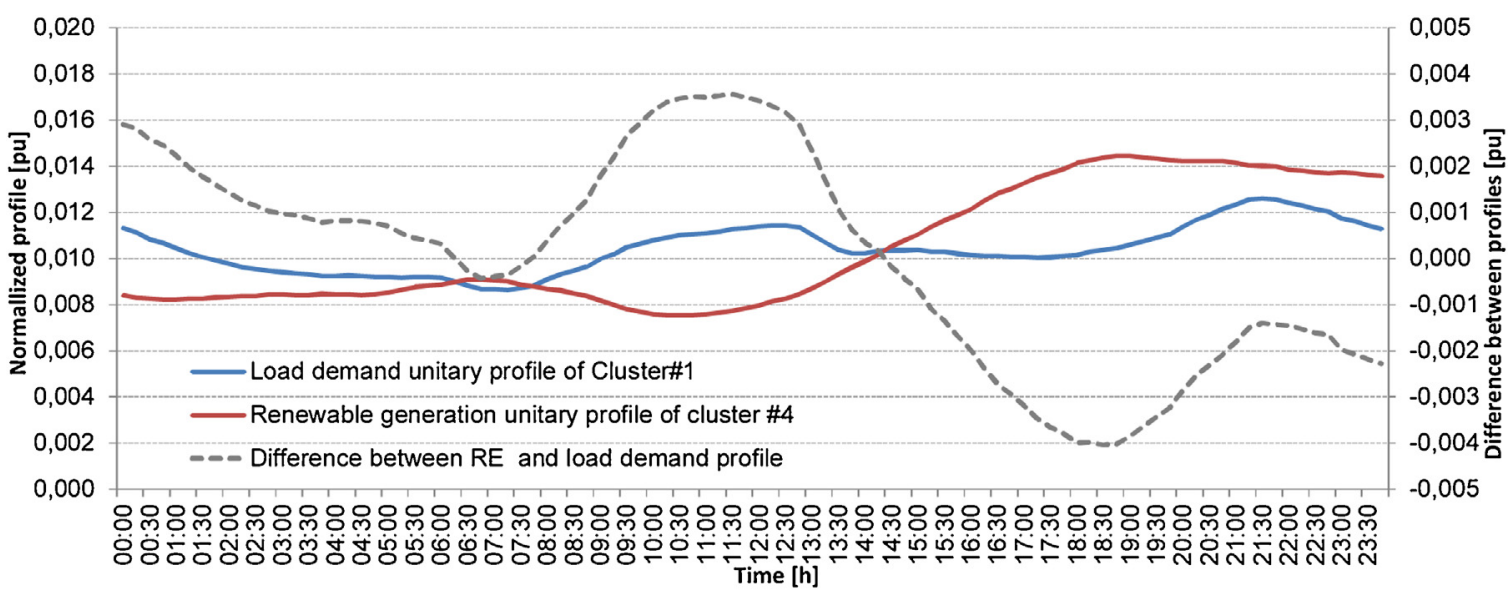

Fig. 6. Analysis of the difference between load demand prototype\#1 and wind generation prototype\#4.

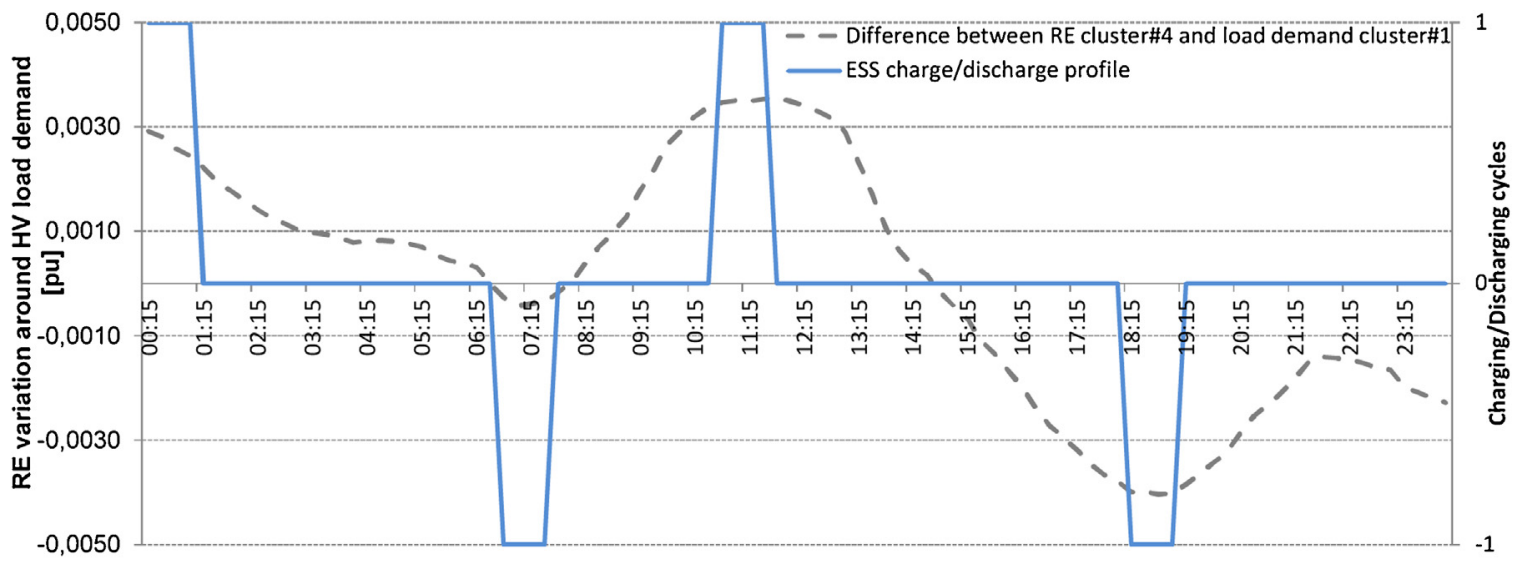

Fig. 7. Renewable integration considering the difference between load demand prototype \#1 and wind generation prototype\#4.

Given the individual cell dimensions of $7.25 \times 160 \times 227 \mathrm{~mm}(\mathrm{~A}$. Systems, 2012), the proposed solution required roughly $0.1 \mathrm{~m}^{3}$ for the battery systems (a battery pack of two Rows of 180 cells, with a total capacity of $22008 \mathrm{Wh}$ ) without power converter, a volume which could be easily integrated in any power transformer facility.

According to several manufacturers, a plausible $90 \%$ efficiency can be expected for the power converter (NEC, 2013) when performing a complete charge/discharge cycle, assuming a nominal discharging capacity of $20.85 \mathrm{~kW}$ and requiring a charging power of $23.17 \mathrm{~kW}$ per power transformer.

The system cost assessment was based on the online price information of the considered technology (BuyA123baterries, 2014), resulting in a unitary cell price of roughly $51.70 €$.

Considering the total of 360 cells, the capital cost of the battery is $18612.00 €$. Regarding the power converter, an estimated cost of $6949.80 €$ was obtained from (Vasconcelos et al., 2012). The total $\operatorname{cost}\left(c_{c}\right)$ of the storage system can then be accounted in $25561.80 €$.

$C R F=\frac{d(1+d)^{n}}{(1+d)^{n}-1}=\frac{d}{1-(1+d)^{-n}}$

The capital recovery factor $\left(\mathrm{CRF}^{10}\right)$ could be defined as in Eq. (5),where $d$ is the annual interest rate and $n$ is the lifetime in years:

Using the CRF for an interest rate of $8 \%$ and a lifetime of 15 years, considering the estimated number of cycles suggested by the management schemes defined in the previous section, the resulting CRF

${ }^{10} \mathrm{CRF}-$ capital recovery factor. is 0.1168 , leading to an annualized capital cost of $2986.37 €$ when applying Eq. (6)

$c_{a c}=c_{c} C R F$

\subsection{Network characterization}

As a case study the authors used the network data of the IEEE 69 bus three-phase balanced $12.66 \mathrm{kV}$ radial distribution system (Vitorino et al., 2013b; Vitorino, Jorge et al., 2009), a welldocumented network, often used for research purposes.

The network was formed by an 8 MVA substation and 69 nodes, of which 48 are load-points (distribution transformers) with a total load of 3.8 MW and 2.69 MVAr (peak period). The network, in its radial configuration, had all the boundary tie-switches in the open position.

As shown in Fig. 8, the proposed radial distribution network includes 48 distribution power transformers which the decision maker considers possible locations for the ESS units based on available space.

To test the proposed methodology, data from different sources regarding the Portuguese market were used. The information regarding market electricity prices was extracted from "The Iberian Energy Derivatives Market Exchange or MIBEL" website. The distribution load demand data, derived from an annual measurement at the Pinheiros substation located in the city of Leiria in Portugal, were kindly provided by EDP Distribuição, the Portuguese distribution system operator. Finally, the renewable generation data, in this case regarding only wind as the main intermittent source, were 


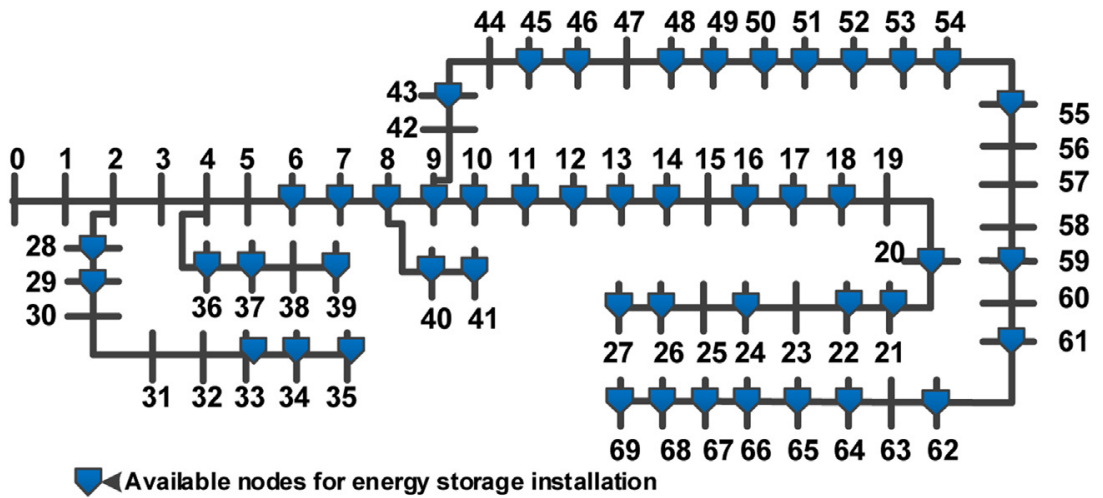

Fig. 8. $12.66 \mathrm{kV}$ radial distribution systems.

extracted from the information center website of the Portuguese Transmission Operator.

\section{Results and discussion}

As mentioned before each management scheme produced 25 scenarios, so a total of 75 scenarios, with different profiles of electricity prices, load demand and wind power generation were used to obtain sets of solutions, Pareto front, with locations for placing the batteries.

In order to help the decision maker to find the objectives and the management scheme that corresponds to the highest marginal economic benefit, and considering the relation between NSAC and NERB, a gradient index operator was defined, hereafter called NSACvSNERB. This index quantifies the slope of the line defined by NSAC and NERB operators.

As an example, in Table 7 presents the first five scenarios (based on management scheme $A$ ). This should be compared with the associated NEL and NVqmd without storage, $7670.98 \mathrm{~kW}$ and $0.0813 \mathrm{pu}$, respectively.

For example, by comparing the NSACvSNERB gradient shown in Table 7 for scenarios 5 and $2,0.127 \%$ and $0.019 \%$, respectively, it becomes clear that for the same load demand profile and the same investment, the ESS management scheme may lead to substantially different benefits.

The best daily losses (NEL) reduction is also associated with scenario 5 , corresponding to $65.03 \mathrm{~kW}$ less than the original value without storage.

The global results of the 75 scenarios are summarized in Table 8, where management scheme $A$ is recognizable as the one with the highest economic benefit. The integration of renewable energy, namely wind generation, can lead to some NEL and NVqmd reduction and NERB reduced benefit and should be subject to a careful analysis, since management scheme $C$ presented some of the worst results.

As expected in the management scheme B related scenarios the highest NEL reductions were obtained, as far as the highest economic benefit occurs with management scheme $A$.

It should be noted that the extreme values presented both for NEL and NERB are related to similar numbers of distributed ESS units installed, except regarding the maximum NEL value in management scheme $\mathrm{C}$, returning substantially different results.

The obtained benefits were quite dependent of the scenarios and management schemes, showing that these definitions are essential for the analysis. The optimization process performed a wide range search, finding solutions with extreme values of the objective functions.
For all the studied scenarios, the range of results shows that the installed capacity influence on the voltage deviation is negligible. It was, therefore, disregarded for detailed observation.

In order to correctly interpret the graphical representation in Fig. 9, the following issues must be taken into consideration:

- The marked dot in Fig. 9, corresponds to the ideal optimum, corresponding to the simultaneous minimization of NEL and NSAC and maximization of NERB, which is not a realistic solution;

- All the presented solutions are non-dominated and therefore there is no single solution better than the others in all aspects;

- The ultimate choice depends on the stakeholder that assumes the decision maker's role. It may, therefore, take different paths.

The different preferences of different stakeholders are a consequence of their different motivations. The authors assume that the stakeholders who can benefit from the developed methodology are the distribution system operator and a private investor, considering the proposals in "Framework for trading stored energy" Section 3 of the current paper, the government or an energy sector regulator acting on its behalf;

Technical issues, such as reducing the NEL and NVqmv, will be privileged by the distribution system operator. On the other hand, a private investor will be interested in maximizing NERB.

Finally, the energy sector regulator will tend to a balancing position between the interests of the other stakeholders, adding societal concerns. This societal perspective, as represented by the government/regulator, was mostly used for analyzing the results. In this context the proposed tool can play an assisting role in the definition of a regulating framework for distributed electric ESS deployment and market integration.

The distribution of solutions depicted in Fig. 9 defines a convex curve, which means that there is a point in the curve where an increase of investment will scarcely contribute to decrease NEL.

In Fig. 10, where only NEL versus NSAC are represented, it is possible to verify that for investments higher than roughly $100000 €$ NEL will increase. For investments between roughly $70000 €$ and $100000 €$, NEL impact may decrease or increase and therefore a careful analysis should be performed to the other two objectives.

If, for example, the decision maker is a private investor, he will likely tend to choose the solution that will return higher economic benefit despite the NEL, as shown in Fig. 11. However, if the decision maker is the distribution system operator, he may likely choose the solution with less investment that causes the highest impact on NEL, as shown in Fig. 10.

On the other hand, if the decision maker is the energy sector regulator, he has to analyze results and to define a set of possible solutions that both satisfy the distribution system operator and the 
Table 7

Results summary table for simulation of load demand prototype \#1 combined with the five charge/discharge vectors based on energy rate prototypes.

\begin{tabular}{|c|c|c|c|c|c|c|c|c|c|}
\hline \multirow[t]{2}{*}{ Simulation/Scenario } & \multicolumn{2}{|l|}{ NEL } & \multicolumn{2}{|l|}{ NVqmd } & \multicolumn{2}{|l|}{ NSAC } & \multicolumn{2}{|l|}{ NERB } & \multirow[t]{2}{*}{ NSACvsNERB Gradient } \\
\hline & Min. & Max. & Min. & Max. & Min. & Max. & Min. & Max. & \\
\hline 1 & 7670.50 & 7699.93 & 0.0813 & 0.0814 & 11945.48 & 131400.28 & 3.29 & 36.19 & $0.028 \%$ \\
\hline 2 & 7669.76 & 7689.16 & 0.0813 & 0.0813 & 2986.37 & 119454.80 & 0.57 & 22.71 & $0.019 \%$ \\
\hline 3 & 7669.77 & 7694.17 & 0.0813 & 0.0814 & 5972.74 & 128413.91 & 1.49 & 31.95 & $0.025 \%$ \\
\hline 4 & 7669.36 & 7701.51 & 0.0813 & 0.0814 & 5972.74 & 140359.39 & 1.51 & 35.51 & $0.025 \%$ \\
\hline 5 & 7605.96 & 7646.27 & 0.0808 & 0.0812 & 14931.85 & 137373.02 & 19.00 & 174.78 & $0.127 \%$ \\
\hline
\end{tabular}

Table 8

Global summary table of the 75 simulations.

\begin{tabular}{|c|c|c|c|c|c|c|c|c|c|c|}
\hline \multirow[t]{2}{*}{ Management scheme: } & \multicolumn{2}{|l|}{ NEL } & \multicolumn{2}{|l|}{ NVqmd } & \multicolumn{2}{|l|}{ NSAC } & \multicolumn{2}{|l|}{ NERB } & \multicolumn{2}{|c|}{ NSACvsNERB } \\
\hline & Min. & Max. & Min. & Max. & Min. & Max. & Min. & Max. & Min. & Max. \\
\hline A & 7188.66 & 8329.08 & 0.0754 & 0.0835 & 2986.37 & 140359.39 & 0.57 & 178.58 & $0.019 \%$ & $0.127 \%$ \\
\hline Simulation no. & 24 & 12 & 25 & 13 & 2 & 4 & 2 & 25 & 2 & 5 \\
\hline Variation & $0.61 \%$ & $0.07 \%$ & $0.57 \%$ & $-0.04 \%$ & - & - & - & - & - & - \\
\hline No. ESS units & 41 & 3 & 47 & 43 & 1 & 47 & 1 & 47 & - & - \\
\hline B & 7180.09 & 8324.07 & 0.0758 & 0.0835 & 2986.37 & 137373.02 & 1.01 & 162.11 & $0.018 \%$ & $0.126 \%$ \\
\hline Simulation no. & 40 & 43 & 45 & 43 & 31 & 35 & 31 & 47 & 35 & 47 \\
\hline Variation & $0.73 \%$ & $0.13 \%$ & $0.02 \%$ & $-0.03 \%$ & - & - & - & - & - & - \\
\hline No. ESS units & 40 & 5 & 18 & 44 & 1 & 46 & 1 & 43 & - & - \\
\hline C & 7183.48 & 8421.73 & 0.0758 & 0.0836 & 2986.37 & 140359.39 & 0.34 & 56.53 & $0.012 \%$ & $0.043 \%$ \\
\hline Simulation no. & 71 & 64 & 71 & 64 & 54 & 60 & 55 & 69 & 55 & 69 \\
\hline Variation & $0.68 \%$ & $-1.04 \%$ & $0.02 \%$ & $-0.24 \%$ & - & - & - & - & - & - \\
\hline No. ESS units & 40 & 46 & 16 & 46 & 1 & 47 & 1 & 44 & - & - \\
\hline
\end{tabular}

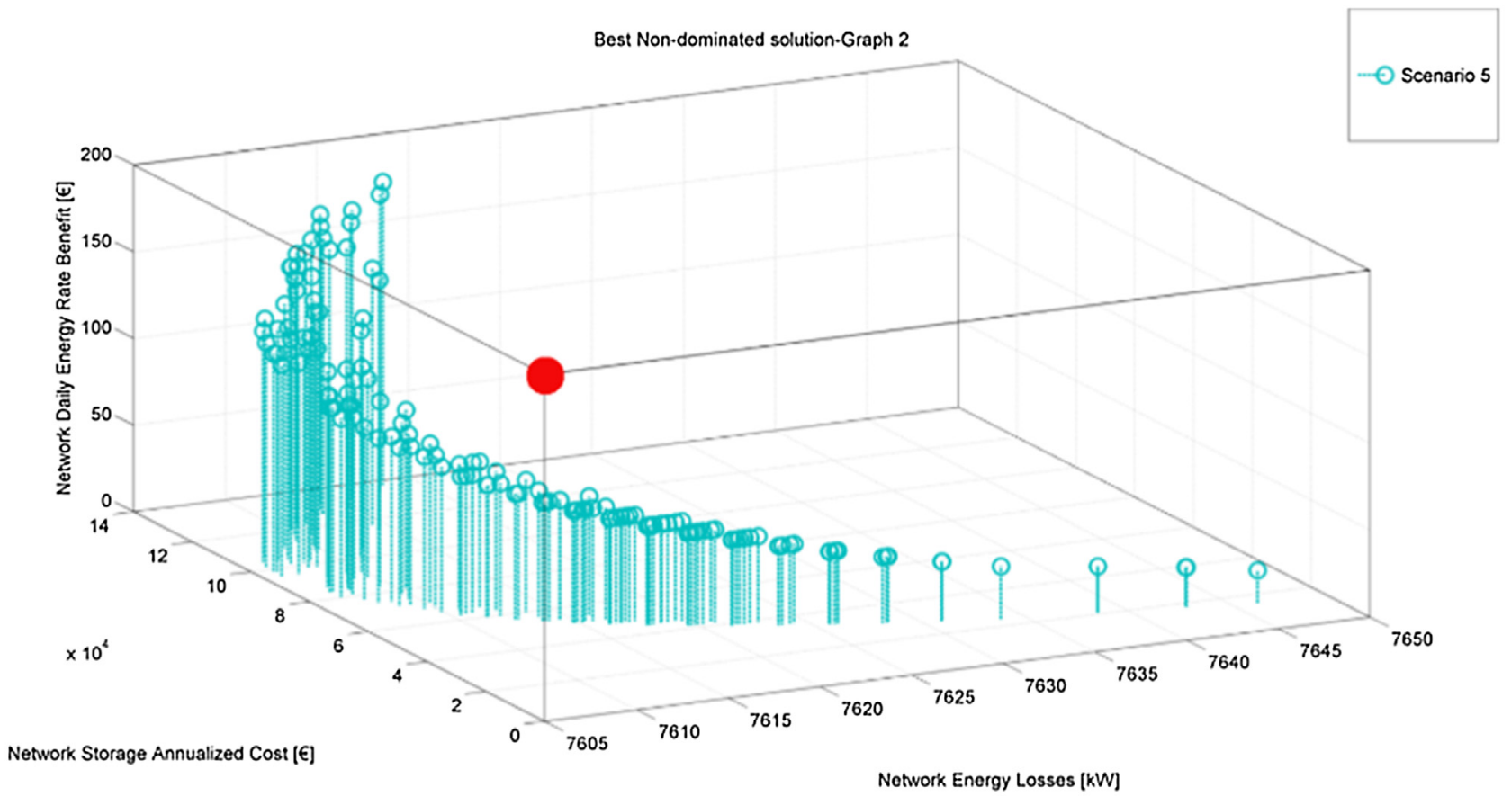

Fig. 9. Isometric view of scenario 5 results considering NEL, NSAC and NERB.

private investor as well as guarantee the most beneficial societal impact. Therefore he may choose solutions closer to the turning point of the Pareto front, specially solutions with NERB roughly around $120 € /$ day, as shown in Fig. 11.

Considering the daily diagram and its associated impact on power losses, results have shown a greater influence of storage, as presented in Fig. 12 also representing maximum, mean and minimum power losses. Although with a small positive net benefit, if the power losses management is the goal, storage may help to achieve that purpose.
Although the impacts of the usage of storage in terms of energy losses were quite low for the case study, in certain time periods, the reduction in instantaneous power losses was significant, achieving $-16 \%$ during the period when storage was contributing to peak demand.

Fig. 12 results prove the aftermath positive impact that storage may have, as summarized in Table 8 , presenting the potential of storage to provide power services to the network due to its fast response and flexibility.

Fig. 13 shows the $1 \mathrm{~h}$ charge/discharge profile considered in simulation 48 , indicating that power services could be provided by this 


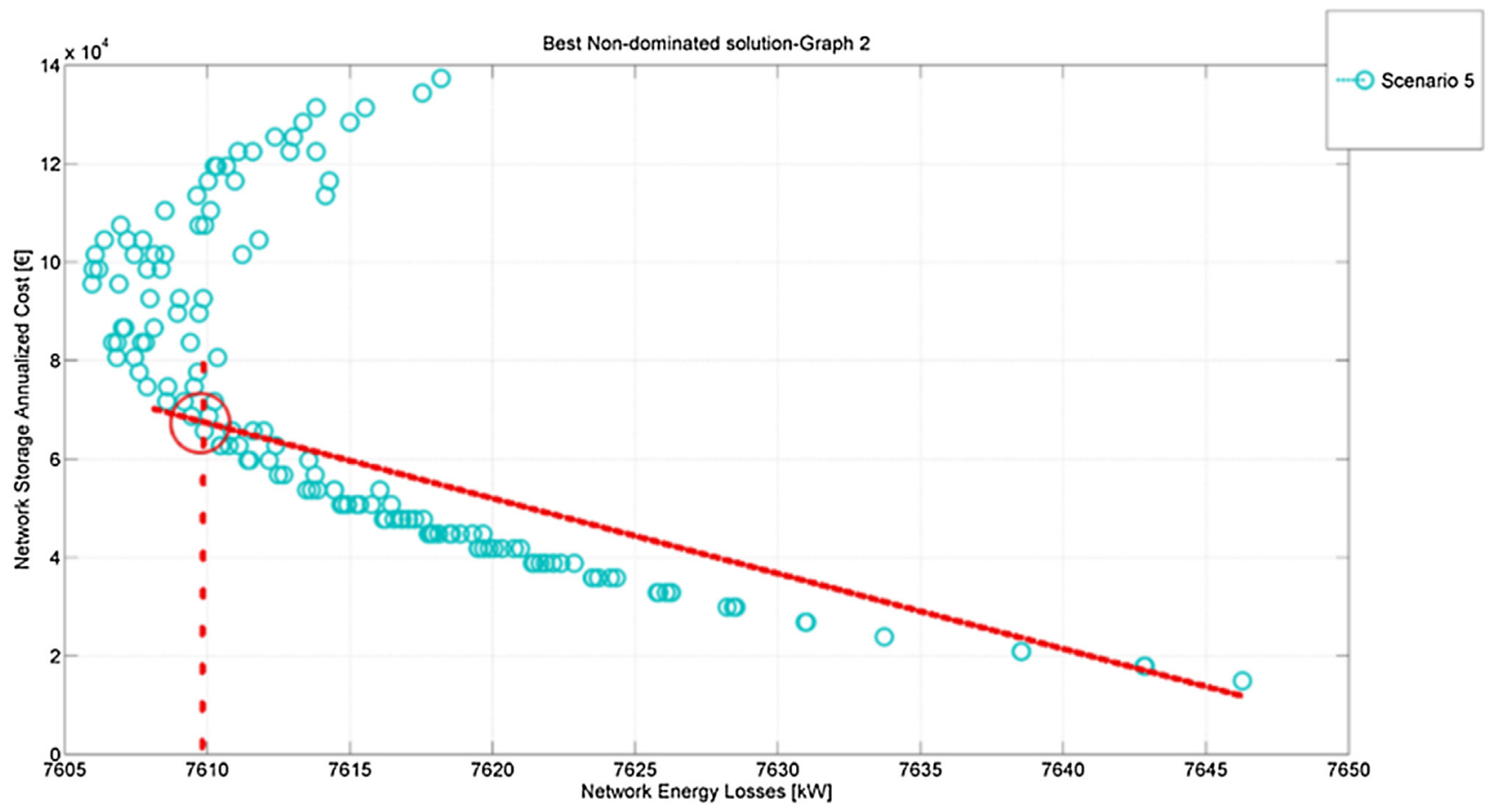

Fig. 10. NEL versus NSAC in simulation 5 (energy rate prototype \#5).

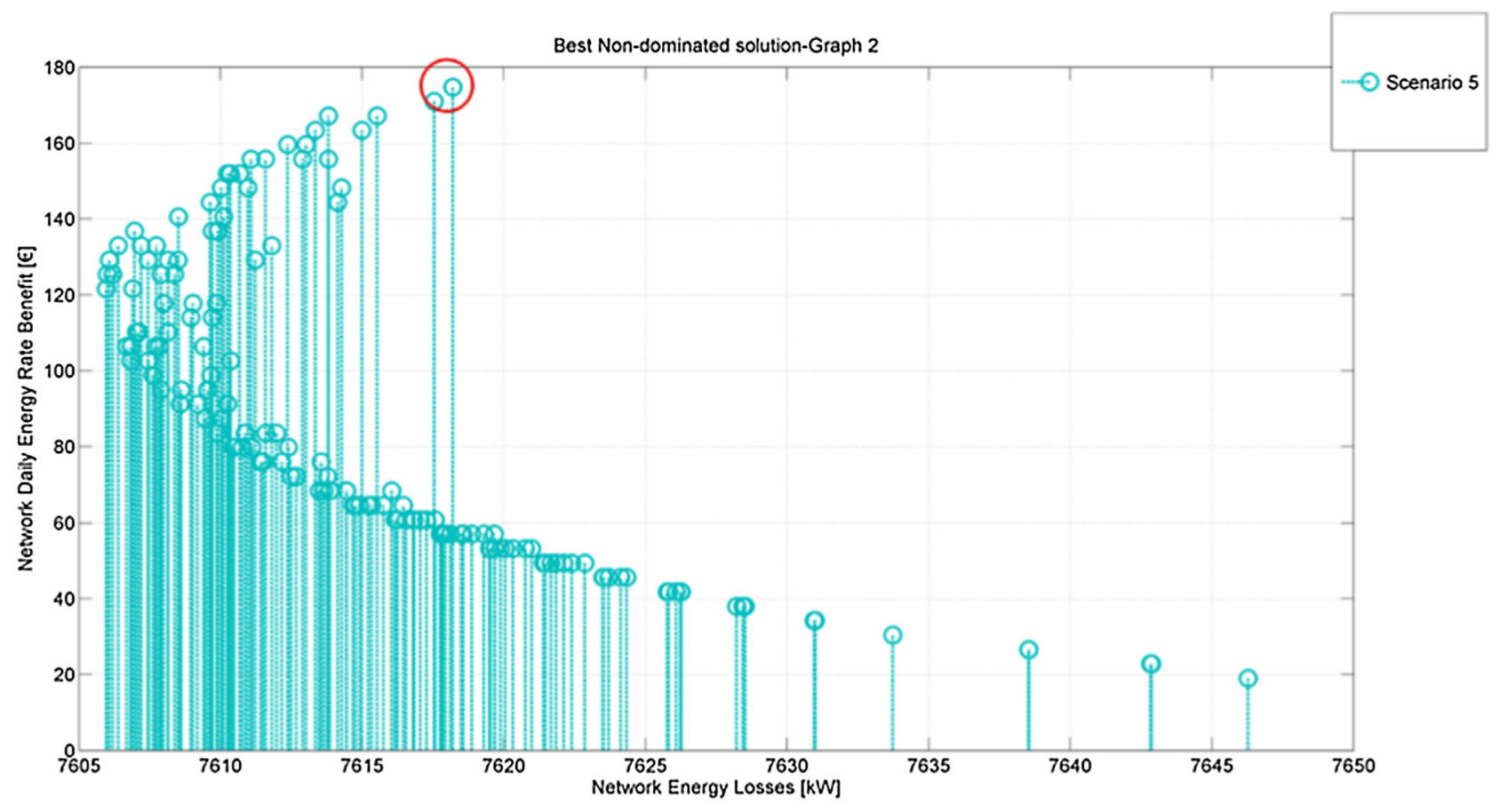

Fig. 11. NEL versus NERB in simulation 5 (energy rate prototype \#5) marking the possible aim of a private investor.

type of solutions. With poor results in terms of NERB, a capacity reserve tariff may help the exploitation of ESS by increasing the daily income as well as contributing to augment the network reliability.

Results showed that ESS may have an important role in the network management, power losses and the substation peak power in critical periods. The authors believe that the increase of the round-trip efficiency would increase the interest for network management ESS applications, especially in regard to energy services. The obtained results show that acquisition costs are the main lim- itation for ESS viability as previously noted in Dufo-López and Bernal-Agustín (2015).

\section{Conclusions}

This paper presents a multiobjective approach to support decision on the best location of energy storage devices on an electricity distribution network, also providing the decision maker information on economic and technical impacts of possible management schemes of charge/discharge operations. 


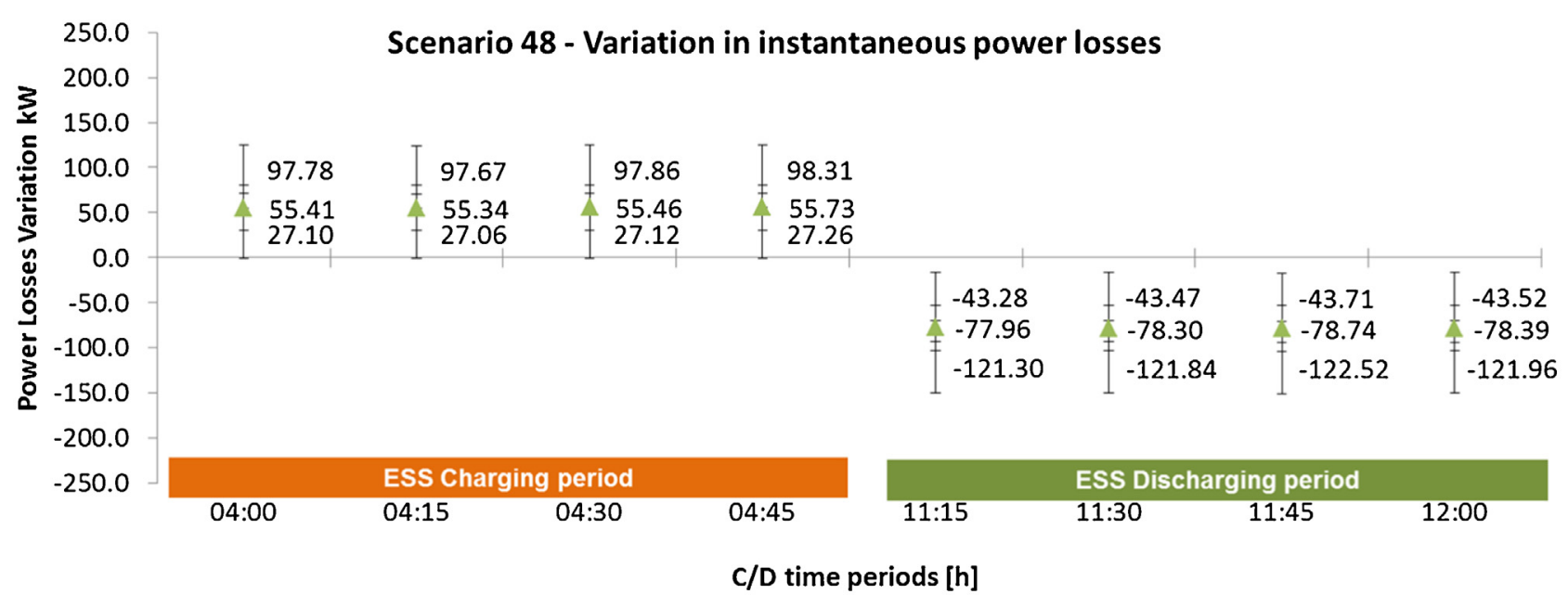

Fig. 12. Numeric daily variation of NEL during charge/discharge periods in simulation 48 .

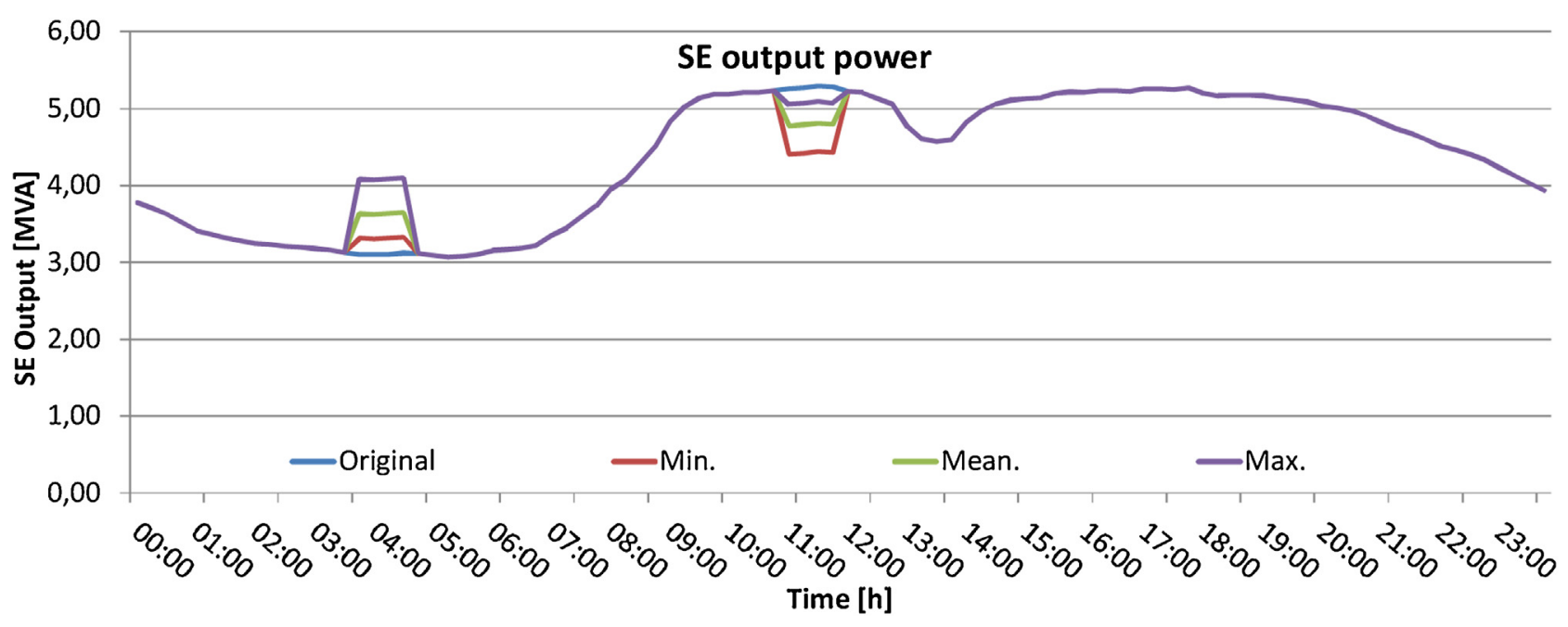

Fig. 13. Substation output power variation non-dominated solutions in simulation 48 .

Considering four objectives, namely regarding network energy losses, energy rate benefit, voltage quadratic mean deviation and storage annualized cost, and the combinatorial nature of the problem, which makes it difficult to define a complete mathematical model, the NSGAII algorithm proved to be a suitable optimization method. For the present case study, the NEL and NVqmd objectives presented a very similar variation among solutions, leading to realize that the consideration of three objectives was enough for the problem under analysis. Nevertheless, further studies are needed to assess whether the fourth objective is effectively redundant.

A future research direction will consider the need to represent the scheduling of charge and discharge periods, as decision variables, then including their choice as part of the optimization process output.

Considering the high cost of investment and the high number of possible scenarios, the authors propose the designated NSACvsNERB gradient index to facilitate the analysis.

The presented work also unveiled the need of having a legal framework to stimulate market players to invest on energy storage. Assuming one of the main objectives as enhancing the penetration of renewable energy by storing energy generated at periods of supply surplus to be used when generation is limited, the energy recovered from energy storage could be rewarded on an equiva- lent basis. A complementary capacity tariff is also suggested to help increasing the income of using energy storage systems.

As a final example of the relevance of the work, some simulated management schemes, aiming for an increased use of renewable energy, introduced negative consequences in the network operation, namely by increasing energy losses. A tool like the one proposed could help to better place the distributed electric energy storage system units in order to achieve minor or zero negative impacts regarding NEL or NVqmd while maximizing profits from the difference in tariffs.

Future work regarding the charging/discharging profile optimization should be pursued in order to suggest to the decision maker an alternative profile for the system.

\section{Acknowledgments}

This work has been framed under the Energy for Sustainability Initiative of the University of Coimbra and supported by the Energy and Mobility for Sustainable Regions Project CENTRO-07-0224FEDER-002004, co-funded by the European Regional Development Fund (ERDF) through the «Programa Operacional Regional do Centro 2007-2013 (PORC)», in the framework of the "Sistema de Apoio a Entidades do Sistema Científico e Tecnológico Nacional», and by 
the "Fundação para a Ciência e Tecnologia». The work was also funded by the "Fundação para a Ciência e Tecnologia» under PEstOE/EEI/UI0308/2014 and UID/MULTI/00308/2013.

\section{References}

A. Systems. (2012). Nanophosphate lithium ion prismatic pouch cell. pp. 1-2. A123 Systems Inc.

A123 Systems, I. (2013). Nanophosphate Basics: An Overview of the Structure, Properties and Benefits of A123 Systems' Proprietary Lithium Ion Battery Technology. Retrieved from https://www.neces.com/assets/A123-Systems_ Nanophosphate-overview-whitepaper_FINAL1.pdf.

Almeida, P. M. R., Lopes, J. A. P., Soares, F. J., \& Seca, L. (2011). Electric vehicles participating in frequency control: operating islanded systems with large penetration of renewable power sources. 2011 IEEE Trondheim PowerTech, 1-6.

Battistelli, C., Baringo, L., \& Conejo, A. J. (2012). Optimal energy management of small electric energy systems including V2G facilities and renewable energy sources. Electric Power Systems Research, 92, 50-59.

Bradbury, K., Pratson, L., \& Patiño-Echeverri, D. (2014). Economic viability of energy storage systems based on price arbitrage potential in real-time U.S. electricity markets. Applied Energy, 114, 512-519.

BuyA123baterries. (2014). BuyA123batteries authorized online reseller of A123 energy solutions cells \& modules. Available: http://www.buya123batteries.com/ category_s/1825.htm Accessed 15.04.14

Chen, T., Hsieh, T., Yang, N.-C., Yang, J., \& Liao, C. (2013). Evaluation of advantages of an energy storage system using recycled EV batteries. International Journal of Electrical Power E' Energy Systems, 45(1), 264-270.

Deb, K., Pratap, A., Agarwal, S., \& Meyarivan, T. (2002). A fast and elitist multiobjective genetic algorithm: NSGA-II. IEEE Transactions on Evolutionary Computation, 6(2), 182-197.

Divya, K. C., \& Østergaard, J. (2009). Battery energy storage technology for power systems-an overview. Electric Power Systems Research, 79(4), 511-520.

Divya, K. C., Østergaard, J., Larsen, E., Kern, C., Wittmann, T., \& Weinhold, M. (2010). Integration of electric drive vehicles in the Danish electricity network with high wind power penetration. European Transactions on Electrical Power, 20(7), $872-883$.

Dufo-López, R., \& Bernal-Agustín, J. L. (2015). Techno-economic analysis of grid-connected battery storage. Energy Conversion and Management, 91, 394-404.

EPRI (2010). Electric energy storage technology options: a white paper primer on applications, costs, and benefits, Palo Alto, CA, 1020676, 2010.

ERSE. (2009). Explanatory information note on special regime production (title in portuguese: 'Nota explicativa da informação sobre produção em regime especial'). Lisbon, Portugal: ERSE - Entidade Reguladora dos Serviços Energéticos.

ERSE. (2013). Special regime production (SRP) information. Continental Portugal. Updated data in May 2013. (Title in portuguese: informação sobre producão em regime especial (PRE). Portugal Continental. Dados actualizados a maio de 2013.). Lisbon, Portugal: ERSE-Entidade Reguladora dos Serviços Energéticos.

Everitt, B. S., Landau, S., Leese, M., \& Stahl, D. (2011). Cluster analysis. Chichester, UK: John Wiley \& Sons, Ltd.

Fossati, J. P., Galarza, A., Martín-Villate, A., \& Fontán, L. (2015). A method for optimal sizing energy storage systems for microgrids. Renewable Energy, 77, 539-549.

Gonçalves, J., Martins, A. G., \& Neves, L. M. P. (2013). Potential role of stationary urban distributed storage on the management of power systems. International conference on energy E' environment (ICEE 2013), p. 11.
Gonçalves, J., Vitorino, R. M., Neves, L. M. P., \& Martins, A. G. (2013). Assessment of best location of distributed storage using improved genetic algorithms'. Energy for sustainability 2013 sustainable cities: designing for people and the planet, p. 7.

Ippolito, M. G., Di Silvestre, M. L., Riva Sanseverino, E., Zizzo, G., \& Graditi, G. (2014). Multi-objective optimized management of electrical energy storage systems in an islanded network with renewable energy sources under different design scenarios. Energy, 64, 648-662.

Kempton, W., \& Tomić, J. (2005). Vehicle-to-grid power fundamentals: calculating capacity and net revenue. Journal of Power Sources, 144(1), 268-279.

Lassila, J., Haakana, J., Tikka, V., \& Partanen, J. (2012). Methodology to analyze the economic effects of electric cars as energy storages. IEEE Transactions on Smart Grid, 3(1), 506-516.

Leou, R.-C. (2012). An economic analysis model for the energy storage system applied to a distribution substation. International Journal of Electrical Power \& Energy Systems, 34(1), 132-137.

MIBEL' council of regulators (2011). Regulatory harmonization for the integration of special regime production in the MIBEL and its electrical systems operation (title in portuguese: "Harmonização regulatória da integração da Produção em Regime Especial no MIBEL e na operação dos respectivos,") 2011.

Maimon, O., \& Rokach, L. (Eds.). (2005). Data mining and knowledge discovery handbook. New York: Springer-Verlag.

Mooi, E., \& Sarstedt, M. (2010). Cluster analysis. In A concise guide to market research. pp. 237-284. Berlin, Heidelberg: Springer. http://dx.doi.org/10.1007/ 978-3-642-12541-6_9

NEC (2013). Grid Storage Solution, p. 8.

Ribeiro, P. F., Johnson, B. K., Crow, M. L., Arsoy, A., \& Liu, Y. (2001). Energy storage systems for advanced power applications. Proceedings of the IEEE, Vol. 89(12), 1744-1756.

Salvador, S., \& Chan, P. (2004). Determining the number of clusters/segments in hierarchical clustering/segmentation algorithms. Tools with artificial intelligence 2004 ICTAI 2004. 16th IEEE international conference, 576-584.

Schoenung, S. (2011). Energy storage systems cost update a study for the DOE energy storage systems program (Report SAND2011-2730). New Mexico and California: Sandia National Laboratories.

Simon, D. (2013). Evolutionary optimization algorithms: biologically-inspired and population-based approaches to computer intelligence. Hoboken, New Jersey: John Wiley \& Sons Inc.

Sovacool, B. K., \& Hirsh, R. F. (2009). Beyond batteries: an examination of the benefits and barriers to plug-in hybrid electric vehicles (PHEVs) and a vehicle-to-grid (V2G) transition. Energy Policy, 37(3), 1095-1103.

Vartanian, C. (2010). Grid stability battery systems for renewable energy success. 2010 IEEE energy convers. congr. expo., 132-135.

Vasconcelos, J., Ruester, S., He, X., Chong, E., Glachant, J.-M., \& Seventh Framework Programme (European Commission). (2012). Electricity storage: how to facilitate its deployment and operation in the EU final report. Firenze, Italy; Taipei, Taiwan: European University Institute; European Union Centre in Taiwan.

Vitorino, R. M., Neves, L. P., \& Jorge, H. M. (2009). Network reconfiguration to improve reliability and efficiency in distribution systems. 2009 IEEE Bucharest PowerTech, 1-7.

Vitorino, R. M., Jorge, H. M., \& Neves, L. P. (2009). Network reconfiguration using an improved genetic algorithm for loss and reliability optimization in distribution systems, research report no 7/2009. Coimbra: INESC Coimbra.

Vitorino, R. M., Jorge, H. M., \& Neves, L. P. (2013a). Multi-objective optimization using NSGA-II for power distribution system reconfiguration. International Transactions on Electrical Energy Systems, p. n/a-n/a.

Vitorino, R. M., Jorge, H. M., \& Neves, L. P. (2013b). Loss and reliability optimization for power distribution system operation. Electric Power Systems Research, 96, $177-184$. 